\title{
The Pleistocene Anthropoid Apes of South Africa
}

\author{
By Dr. R. Broom, F.R.S., Transvaal Museum, Pretoria, South Africa
}

$D^{\wedge}$ ART'S discovery in 1924 of the fossil ape of Taungs, which he named Australopithecus africanus, opened a new chapter in the history of the origin of man. The type skull, which unfortunately is the only one known from that locality, is that of a five-year-old child, and though there seems little doubt that Dart was right in regarding it as an ape much nearer to man than either the chimpanzee or the gorilla, some European men of science still seem to believe that it is a variety of chimpanzee or a dwarf gorilla, in spite of the fact that the milk teeth are entirely different in structure from those of the living anthropoids, and closely similar to those of man.

In 1936 I discovered, at Sterkfontein, much of an adult skull which I described as Australopithecus transvaalensis. It is clearly allied to the Taungs ape, but there are few points in which a comparison can be made between the two, and I provisionally placed it in the same genus. In the last two years almost continuous exploration has been going on at Sterkfontein, and many interesting further remains have been found, notices of some of which have been published in NATURE.

Until this year, nothing was known of the lower jaw except a beautifully preserved 3rd molar. We still do not know much of the mandible, but we now have a well-preserved 2nd premolar, much of what I regard as a female canine, and the incisor portion of the jaw of a young male, corresponding to a human boy of nine years, with the perfectly preserved crown of an unworn canine. This canine is unlike that of any ape at present known, but there seems little doubt that it is rightly identified as that of the male $A$. transvaalensis, from the resemblance it bears in a number of respects to the canine, which I regard as the lower canine of the female. Though little more than the incisor portion of the symphysis is preserved, it shows the sockets of the incisors, and reveals the interesting fact that the lateral incisors are considerably larger than the central ones. The shape of the symphysis is so different from that of the Taungs ape that it seems advisable to place $A$. transvaalensis in a distinct genus, for which the name Plesianthropus is proposed.

In June of this year a most important new discovery was made. A schoolboy, Gert Terblanche, found in an outcrop of bone breccia near the top of a hill, a couple of miles from the Sterkfontein caves, much of the skull and lower jaw of a new type of anthropoid. Not realizing the value of the find, he damaged the specimen considerably in hammering it out of the rock. The palate with one molar tooth he gave to Mr. Barlow at Sterkfontein, from whom I obtained it. Recognizing that some of the teeth had recently been broken off, and that there must be other parts of the skull

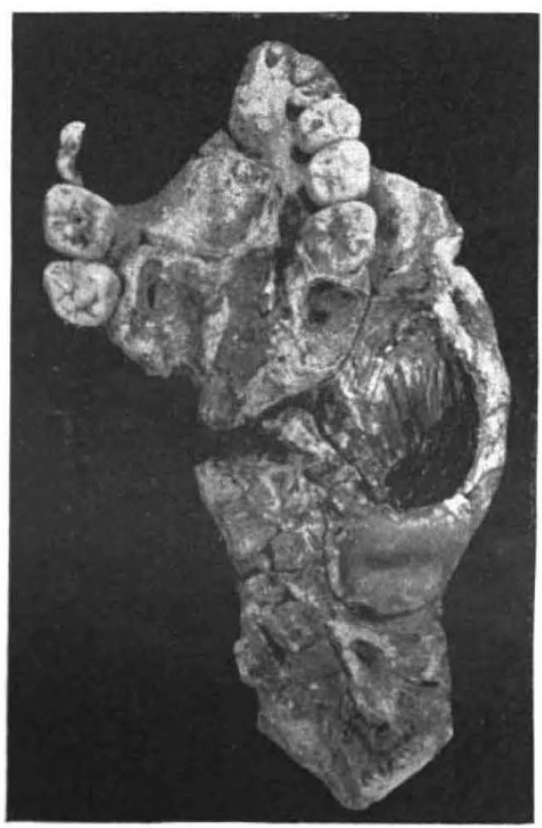

Fig. 1.

Palatal view OF SKULL OF Paranthropus robustus Broom, about $\frac{1}{2}$ NATURAL SIze. THE TEETH OF THE LEFT SIDE HAVE BEEN WEATHERED OFF, BUT ARE REPLACED IN WHAT MUST HAVE BEEN NEARLY THEIR ORIGINAL POSITION. PART OF THE SOCKRT OF LEFT $m^{3}$ IS PRESERVED.

where the palate was found, I had to hunt up the schoolboy. I went to his home two miles off and found that he was at school another two miles away, and his mother told me that he had four beautiful teeth with him. I naturally went to the school, and found the boy with four of what are perhaps the most valuable teeth in the world in his trouser pocket. He told me that there were more bits of the skull on the hillside. After school he took me to the place and I gathered every scrap I could find; and when these were later examined and cleaned and joined up, I found I had not only the nearly perfect palate with most of the teeth, but also practically the whole of the left side of the lower half of the skull and the nearly complete right lower jaw. The only missing parts 
of importance are the halves of two molars, the crown of the left lst upper premolar and the crown of the right lower canine. Those I still hope to discover. As, however, we have impressions in the matrix of some of the missing teeth and parts, we know nearly the complete dentition.

The skull is that of a large ape, larger than most male chimpanzees and nearly as large as

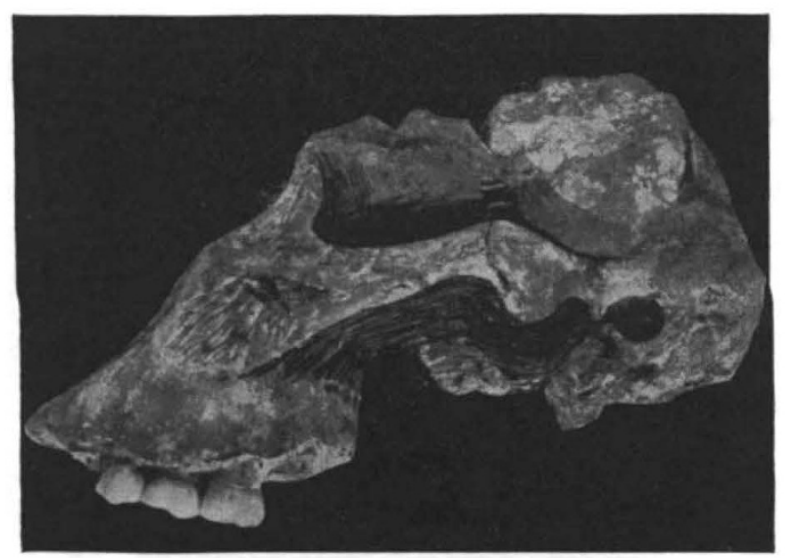

Fig. 2.

SIDE VIEW OF SKuLI OF Paranthropus robustus Broom. About $\frac{1}{2}$ natural size.

most female gorillas; but it differs very greatly from both the living African anthropoids. Much of the palate is preserved in perfect condition. The whole of the left side of the sphenoid bone is also preserved; while the zygomatic arch is nearly complete. The glenoid cavity and the tympanic bone are in perfect preservation, and much of the mastoid region, and part of the occiput with a portion of the left condyle.

The glenoid cavity and the relations to the tympanic bone are of exceptional interest. In the gorilla, the chimpanzee, the orang and the gibbon, the outer part of the tympanic is situated behind the posterior glenoid process. In man, the tympanic is situated mainly below the glenoid process, and even at its outer part it forms the posterior nonarticular part of the glenoid cavity. In the new fossil ape, the condition of the glenoid and tympanic is almost exactly as in man, though the parts are very much larger.

The occipital condyle is in practically the same plane as the external auditory meatus and thus farther forward than in the gorilla and the chimpanzee; which appears to indicate that the ape walked somewhat more erect than the living anthropoids.

From the portion of the brain case preserved, I estimate the volume of the brain to have been about 600 c.c. The face is remarkably flat and much shorter than in the gorilla. A curious bony ridge runs down from the inner border of the large infraorbital foramen.

The molar teeth, as will be seen from the illustrations, differ considerably in shape from those in Plesianthropus transvaalensis, and the 2nd premolar is about half as large again as in the Sterkfontein ape. The upper canine had been lost before fossilization, but it must have been relatively remarkably small, and the incisors, of which we have much of the sockets preserved, were also relatively small. The palate is relatively short and broad, and owing to the small size of the incisors and canines the anterior part is narrowed, and the teeth are arranged more as in man than in any of the living anthropoids. The anterior two-thirds of the right mandible are satisfactorily preserved. The symphyseal region has been broken off behind the canine before fossilization and slightly displaced. The incisors which are lost have been relatively very small, and the lateral ones are scarcely larger than the central. The canine crown is lost, but the impression of its outer side is preserved in the matrix. It is quite a small tooth, and remarkably human in shape. It is clearly very unlike the canine of Plesianthropus transvaalensis. The premolars have rounded crowns without any high well-developed cusps as in the living anthropoids, and are thus fairly similar to those of man, but about twice as large. The 2nd premolar differs very markedly from that of Plesianthropus transvaalensis, and we may thus confidently place the new skull in a new genus and species.

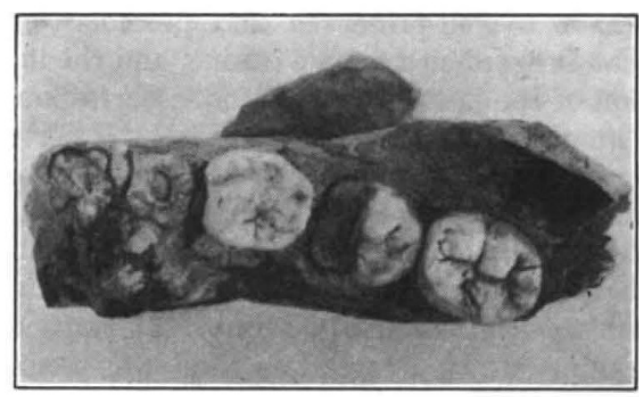

Fig. 3.

OCCLUSAL VIEW OF MOLARS, WITH ROOTS OF PREMOLARS, OF RIGHT MANDIBLE OF Paranthropus robustus BROOM.

The deposit in which the skull was found is the floor of an old cave the walls of which have probably been weathered away thousands of years ago. We may therefore suspect that the deposit is very much older than that in the Sterkfontein caves, and this is confirmed by the associated fauna. It contains a jackal, a baboon, a horse and a hyrax, which are all of different species from those at Sterkfontein, and are most probably all older. 


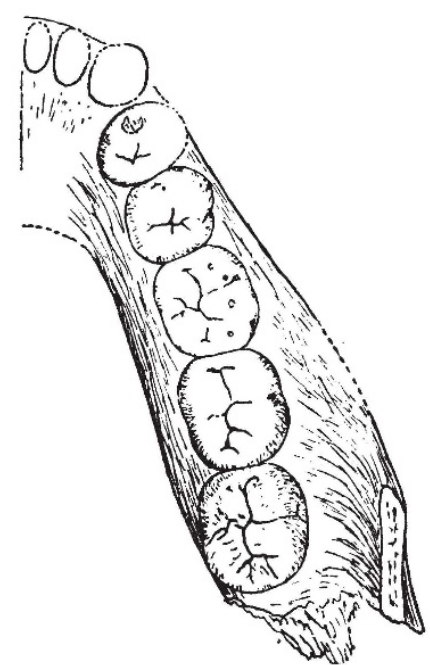

Fig. 4.

Occlusal view of Right Mandible of Paranthropus robustus BROOM. $\frac{3}{4}$ NATURAL SIZE. THE PORTION OF THE JAW WITH CANINE AND INCISOR SOCKETS WAS DETACHED AND IS PLACED IN WHAT WAS PROBABLY ITS ACTUAI RELATIONSHIP.

The skull may be referred to as the Kromdraai (pronounced 'Kromdry') skull, and may be given the name Paranthropus robustus.

It seems probable that the Sterkfontein skull is of Upper Pleistocene age, the Kromdraai skull of Middle Pleistocene and the Taungs skull probably of Lower Pleistocene ; though of course more work will have to be done before the geological ages of any of these skulls can be determined with more than probability.
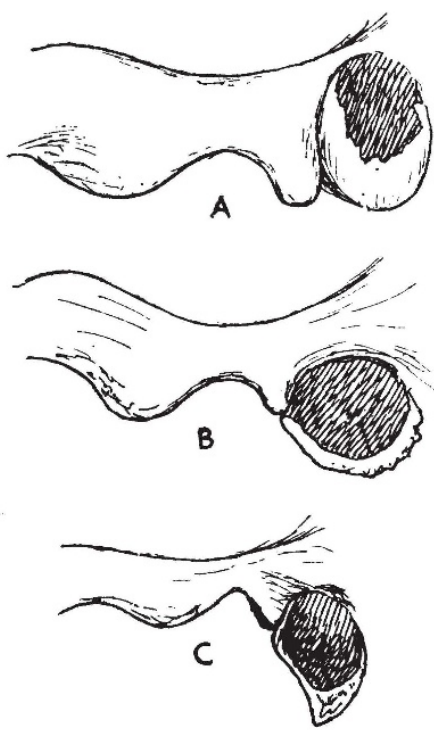

Fig. 5.

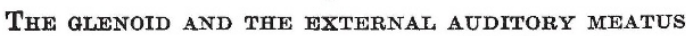
IN (A) A LARge Male gorilla ; (B) Paranthropus robustus; aND $(C)$ A LARGE KORANA MALE. 3 NATURAL SIZE.
Clearly, during the Pleistocene there lived in South Africa a number of large-brained anthropoids which resemble man in the shape of their premolars and in having relatively small canines, and in having the glenoid region, in at least some forms, remarkably human in structure. These Pleistocene apes are probably the modified descendants of forms that may have been widely distributed over Africa in Pliocene times, and it is probably from one of the Pliocene members of the group that man arose.

Quite certainly the conditions in Pleistocene times in South Africa were not unlike those of to-day. The apes lived on the plains and among the rocky krantzes. At Taungs most probably the apes lived in the caves. The associated animal remains seem to be the kitchen midden of Australopithecus.

At Sterkfontein and Kromdraai the larger bones in the caves seem all to have been introduced by

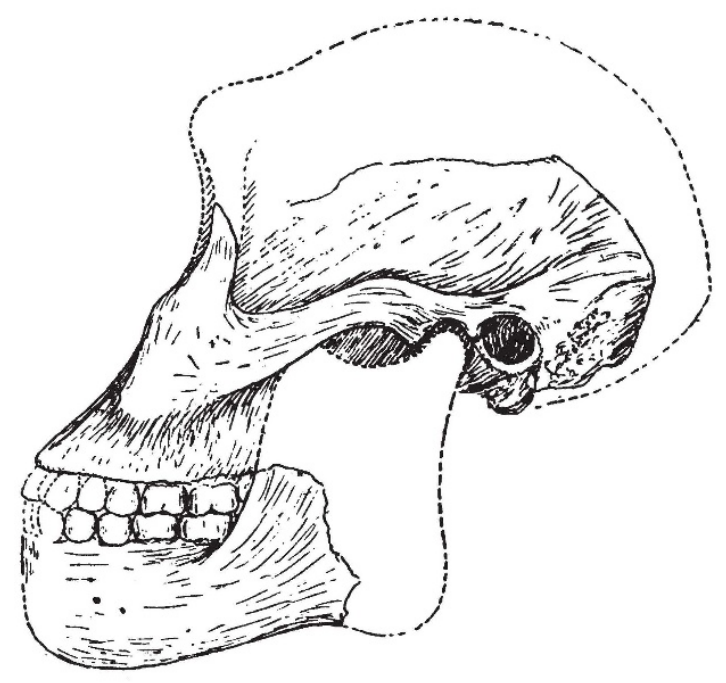

Fig. 6.

SIDE VIEW OF SKULL OF Paranthropus robustus Broom. $\frac{3}{8}$ natural size. Restored. The parts IN LINE ARE KNOWN.

carnivorous animals and the small bones by owls. Nearly every bone of the larger animals has been broken in pieces. No perfect limb bone has been found, and most teeth are detached from the jaws and many of the teeth have also been broken before fossilization.

We have now a fairly good knowledge of the faunas associated with the apes. We know about a dozen fossil mammals from the Taungs caves, all extinct; about thirty mammals from Sterkfontein, nearly all extinct; and we know about a dozen from Kromdraai, all extinct except onethe living porcupine. 